\title{
EFFECTIVENESS OF ADDITION OF DEXAMETHASONE TO 0.5\% ROPIVACAINE IN PROVIDING PERIOPERATIVE ANALGESIA FOR SUPRA CLAVICULAR BRACHIAL PLEXUS BLOCK
}

\author{
Deepraj Singh Bais ${ }^{1}$, Geetha $C^{2}$, Amisha Kawale ${ }^{3}$
}

\section{HOW TO CITE THIS ARTICLE:}

Deepraj Singh Bais, Geetha C, Amisha Kawale. "Effectiveness of Addition of Dexamethasone to 0.5\% Ropivacaine in Providing Perioperative Analgesia for Supra Clavicular Brachial Plexus Block". Journal of Evolution of Medical and Dental Sciences 2014; Vol. 3, Issue 10, March 10; Page: 2456-2464, D0I: 10.14260/jemds/2014/2158

\begin{abstract}
Adjuncts to local anesthetics for brachial plexus block may enhance the quality and duration of analgesia. This study tested the hypothesis that adding dexamethasone significantly prolongs the duration of ropivacaine A prospective, randomized, single blinded study was conducted on 50 ASA I or II patients undergoing upper limb surgeries under supra clavicular brachial plexus block. Patients were randomly divided into 2 groups. Patients in group $\mathrm{R}(\mathrm{n}=25)$ were administered $30 \mathrm{ml}$ of $0.5 \%$ Ropivacaine and $2 \mathrm{ml}$ of normal saline and group RD ( $\mathrm{n}=25)$ were given $30 \mathrm{ml}$ of $0.5 \%$ Ropivacaine and $8 \mathrm{mg}(2 \mathrm{ml})$ Dexamethasone. The onset time and duration of sensory and motor blockade were recorded. Hemodynamic variables (i.e., heart rate, non-invasive blood pressure and oxygen saturation) and rescue analgesic requirements were recorded for $24 \mathrm{hrs}$. postoperatively. RESULTS: Addition of Dexamethasone as adjunct to Ropivocaine significantly prolonged the duration of sensory block which was $9.44 \pm 0.8$ hours in group $\mathrm{R}$ and $19.52 \pm 1.5$ hours in group RD, in postoperative period without much change in onset and duration of motor block. CONCLUSION: Addition of dexamethasone to ropivacaine in supraclavicular brachial plexus block significantly prolongs the duration of analgesia and motor block in patients undergoing upper limb surgeries and is a remarkably safe and cost effective method of providing postoperative analgesia. Rescue analgesic requirements were significantly less in group RD compared to group R. confirming the significant prolongation of analgesia during intraoperative and postoperative period. Hemodynamic parameters did not differ between groups in the post-operative period.
\end{abstract}

KEYWORDS: Brachial plexus block, Ropivacaine, Dexamethasone, analgesia.

INTRODUCTION: Brachial plexus block provides a useful alternative to general anesthesia for upper limb surgeries. Of various local anesthetics, lignocaine and bupivacaine are the most frequently used as it has faster onset and longer duration of action respectively. However there are limitations like shorter duration of action with lignocaine and increased incidence of toxicity with bupivacaine. ${ }^{1}$

As a result of these limitations, newer local anesthetics like Ropivacaine have been introduced. Bupivacaine is a racemic mixture of stereoisomers, whereas ropivacaine is supplied as the pure S (-) isomer. Chemically, however, they are similar amide class local anesthetics, differing only in the number of carbon atoms on the n-alkyl substituted piperidine ring: bupivacaine has a butyl (4-carbon) group whereas ropivacaine has a propyl (3-carbon) group. This slight difference may in fact be clinically important, as the decreased lipid solubility of ropivacaine is advanced as an explanation for its enhanced tendency to block sensory nerve fibers more readily than motor fibers compared to bupivacaine.

Why dexamethasone would prolong regional anesthesia is a subject of much discussion and speculation. They may act by inhibition of phospholipase A2 as well as changes in cell function 
induced by glucocorticoid receptor activation. Steroids induce some degree of vasoconstriction, so one hypothesis is that it acts in a similar manner to epinephrine by reducing local anesthetic absorption. A more attractive hypothesis holds that dexamethasone may act locally on nociceptive Cfibers (via glucocorticoid receptors) to increase the activity of inhibitory potassium channels, thus decreasing their activity. ${ }^{2}$

Many other adjuvants have been added in the effort to prolong the duration of action of local anesthetics like tramadol, butorphanol ${ }^{3}$, verapamil, methylprednisolone ${ }^{4}$ but by far the addition of dexamethasone has shown promising results.

The present study is being undertaken to evaluate the onset time, duration and analgesic efficacy of dexamethasone - ropivacaine combination compared to plain ropivacaine (0.5\%) for brachial plexus block by supraclavicular approach.

MATERIAL AND METHODS: This study was carried out in Department of Anesthesiology, Osmania General Hospital, Osmania Medical College, Hyderabad. Consent from the ethics committee was obtained. Informed written consent was taken. Result values were recorded using a preset proforma. A prospective, randomized, single blinded study was undertaken. 50 patients posted for upper limb surgeries under supra clavicular block between the age groups of 15 to 45 years undergoing upper limb surgeries under supraclavicular brachial plexus block would be assigned to 2 groups, each containing 25 patients.

Control group - group R: received $30 \mathrm{ml}$ ropivacaine (0.5\%) plus $2 \mathrm{ml}$ normal saline and Study group - group RD: received $30 \mathrm{ml}$ ropivacaine (0.5\%) plus $2 \mathrm{ml}$ dexamethasone (8 $\mathrm{mg})$.

Inclusion criteria: ASA class I and II, age between 15 to 45 years, systolic blood pressure - 100-139 $\mathrm{mm}$ of $\mathrm{Hg}$, diastolic blood pressure $-60-89 \mathrm{~mm}$ of $\mathrm{Hg}$.

Exclusion criteria: Patients belonging to ASA class III and IV, Infection at the site of injection, presence of co-morbidities, presence of coagulopathies, hypersensitivity to any of the drugs used in this study.

In operation theatre intravenous access established with $18 \mathrm{G}$ cannula on contralateral upper limb under strict aseptic precautions. Equipment used for the procedure included a portable tray covered with sterile towels containing sterile syringes: two $10 \mathrm{ml}$ syringes, hypodermic needles of 5 cm length, $22 \mathrm{G}$, bowl containing povidone iodine and spirit, sponge holding forceps, sterile hole towel, sterile gauze pieces.

Technique of Brachial plexus block: ${ }^{5,6}$ All the necessary equipment for emergency resuscitation was kept ready. Patient was monitored using pulse oximeter, non-invasive blood pressure monitoring in the opposite arm. Patient lays supine, arms by the side and head turned slightly to the other side. The arm to be anesthetized should be adducted, and the hand should be extended along the side toward the ipsilateral knee as far as possible. In the classic technique, the midpoint of the clavicle should be identified and marked. The posterior border of the sternocleidomastoid can be palpated easily when the patient raises the head slightly. The palpating fingers can then roll over the belly of the anterior scalene muscle into the interscalene groove, where a mark should be made 
approximately 1.5 to $2.0 \mathrm{~cm}$ above the midpoint of the clavicle. Palpation of the subclavian artery at this site confirms the landmark. After appropriate preparation and development of a skin wheal, the anesthesiologist stands at the head end of the patient. A 22-gauge, 4-cm needle is directed in a caudad, slightly medial, and posterior direction until a paresthesia or motor response is elicited or the first rib is encountered.

If the first rib is encountered without elicitation of a paresthesia, the needle can be systematically walked anteriorly and posteriorly along the rib until the plexus or the subclavian artery is located. Location of the artery provides a useful landmark; the needle can be withdrawn and reinserted in a more posterolateral direction, which generally results in a paresthesia or motor response. On localization of the brachial plexus, aspiration for blood should be performed before incremental injections of a total volume of $32 \mathrm{ml}$ of the study drug. All the patients would be monitored for anesthesia and analgesia post operatively for $24 \mathrm{hrs}$.

Sensory block was evaluated by pin prick and temperature testing using spirit soaked cotton on skin dermatomes $\mathrm{C} 4$ to T2, whereas motor block was assessed by asking the patient to adduct the shoulder and flex the forearm against gravity. Previous studies observed similar parameters by Desmet.M, Braems.H, Reynvoet. $\mathrm{M}^{7}$ by their work done on intravenous and perineural dexamethasone are equivalent in increasing the analgesic duration of single shot block with ropivacaine for shoulder surgery-a prospective randomized placebo controlled study.

\section{ASSESSMENT OF SENSORY BLOCK:}

\section{1) ONSET OF SENSORY BLOCK:}

a) Subjective Assessment: Time interval between administrations of local anesthetic to the time patient first indicates relief of pain.

b) Objective Assessment: Time interval between administration of local anesthetic to complete analgesia of forearm in relation to the distribution of each major nerve as tested by pinprick over the forearm between elbow and wrist (areas of open wound excluded).

2) DURATION OF SENSORY BLOCK: Duration between time of onset of sensory block to the time when patient first complains of pain at the site of surgery.

\section{ASSESSMENT OF MOTOR BLOCK:}

a) Onset of Motor Block: Time interval between administrations of local anesthetic to the time when finger movements are lost completely.

b) Duration of Motor Block: Duration between the times of loss of finger movements to the time the patient first regains his finger movements.

ASSESSMENT OF PAIN: VERBAL RATING SCALE (VRS) ${ }^{8}$ (table1) was used to assess the level of pain perceived by the patient. A VRS consists of a list of adjectives describing different levels of pain severity. Patients are asked to inspect the list of adjectives and select the word or phrase that best describes their level of pain. 


\begin{tabular}{|c|l|}
\hline SCORE & \multicolumn{1}{|c|}{ INTENSITY } \\
\hline 0 & NO PAIN \\
\hline 1 & MILD PAIN \\
\hline 2 & MODERATE PAIN \\
\hline 3 & SEVERE PAIN \\
\hline 4 & VERY SEVERE PAIN \\
\hline \multicolumn{2}{|c|}{ Table 1: VRS PAIN SCORES } \\
\hline
\end{tabular}

Successful block: we considered our block successful when analgesia was present in all areas supplied by the four major nerves.

Failure: was defined as the absence of sensory block in at least one neural distribution and/or the need of another anesthetic technique to allow surgery.

Intravenous Midazolam $1 \mathrm{mg}$ was given intra operatively for sedation in all patients. IM injections of Diclofenac Sodium would be given as rescue analgesics when patient complains of pain Number of rescue analgesics in $24 \mathrm{hrs}$ of post-operative period would also be recorded.

Statistical analysis: The demographic and clinical data of 50 patients were analyzed by univariate analysis, quantitative data by student't' test. VRS pain scores were analyzed using Mann Whitney Test. SPSS software version 17 of statistical analysis was used in this study. P value of $<0.05$ would be considered statistically significant.

RESULTS: The study done on 50 patients aged between 15 and 45 years posted for forearm surgical procedures to compare the efficacy of plain Ropivacaine vs. Ropivacaine - Dexamethasone combination in providing intra operative and post-operative analgesia. The average age in group $\mathrm{R}$ was $27.68 \pm 7.7$ yrs. with the youngest being 16 yrs. and the oldest being 42 yrs. The average age in group RD was $31.08 \pm 9.4$ yrs. with the youngest being 16 yrs. and the oldest being 45 yrs. There was no statistically significant difference between the two groups in reference to the age distribution.

The time to onset of sensory block which was $14.12 \pm 2.1 \mathrm{~min}$ in group $\mathrm{R}$ and $14.96 \pm 3.0 \mathrm{~min}$ in group RD, the difference of which was not found to be statistically significant.(table 2).

The time to onset of motor block in the two groups and was found to be $18.12 \pm 3.4 \mathrm{~min}$ in group $\mathrm{R}$ and $17.14 \pm 2.9 \mathrm{~min}$ in group $\mathrm{RD}$. The difference was not found to be statistically significant (table 3).

The duration of sensory block which was $9.44 \pm 0.8$ hours in group R and $19.52 \pm 1.5$ hours in group RD. The difference between the two groups was found to be statistically significant.(table 4)(graph 1)

The duration of motor block which was around 7.28 \pm 0.8 hours in group $\mathrm{R}$ and $7.6 \pm 0.7$ hours in group RD. The difference between the two groups was not statistically significant (table 5).

The table 6 shows the variations in the VRS pain scoring system. The scores for the two groups were found to be significantly different between 6 to $12 \mathrm{hrs}$. following institution of the block, with higher pain scores being recorded in group $\mathrm{R}$ due to fade of the block. 


\section{REVIEW ARTICLE}

Rescue analgesics were supplemented in Group R after $7 \mathrm{hrs}$. due to increase in pain and after 20 hrs. in Group RD. Table 7 show the number of rescue analgesics the patients required in $24 \mathrm{hrs}$. post-operative period. The difference was found to be statistically significant.

A total of 6 failed blocks were obtained, 4 in group R and 2 in group RD.

\begin{tabular}{|c|c|c|c|c|}
\hline GROUP & TIME (min) & MEAN \pm S.D. & P value & SIGNIFICANCE \\
\hline $\mathrm{R}$ & 14.12 & $14.1 \pm 2.1$ & \multirow{2}{*}{0.262} & NS \\
\cline { 1 - 3 } $\mathrm{RD}$ & 14.96 & $14.9 \pm 3.0$ & & \\
\cline { 1 - 1 } & \multicolumn{5}{|c|}{ Table 2: ONSET OF SENSORY BLOCK } \\
\hline
\end{tabular}

\begin{tabular}{|c|c|c|c|c|}
\hline GROUP & TIME (min) & MEAN \pm S.D. & P value & SIGNIFICANCE \\
\hline R & 18.12 & $18.1 \pm 3.4$ & \multirow{2}{*}{0.431} & NS \\
\cline { 1 - 3 } RD & 17.14 & $17.4 \pm 2.9$ & & \\
& Table 3: ONSET OF MOTOR BLOCK \\
\hline
\end{tabular}

\begin{tabular}{|c|c|c|c|c|}
\hline GROUP & TIME (hrs.) & MEAN \pm S.D. & P value & SIGNIFICANCE \\
\hline R & 8.44 & $8.4 \pm 0.8$ & \multirow{2}{*}{0.0001} & HS \\
\cline { 1 - 3 } RD & 19.52 & $19.5 \pm 1.5$ & & \\
\\
Table 4: DURATION OF SENSORY BLOCK \\
\hline
\end{tabular}

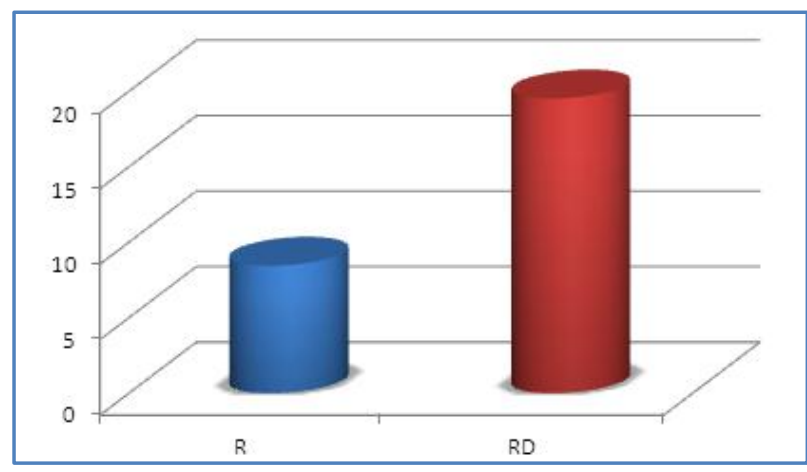

Graph 1: Duration of sensory block

\begin{tabular}{|c|c|c|c|c|}
\hline GROUP & TIME (hrs.) & MEAN \pm S.D. & P value & SIGNIFICANCE \\
\hline R & 7.28 & $7.2 \pm 0.8$ & \multirow{2}{*}{0.240} & NS \\
\cline { 1 - 3 } RD & 7.6 & $7.5 \pm 0.7$ & & \\
\hline \multicolumn{5}{|c}{ Table 5: DURATION OF MOTOR BLOCK } \\
\hline
\end{tabular}

\begin{tabular}{|c|c|c|c|}
\hline TIME & GROUPS & MEAN \pm S.D. & P VALUE \\
\hline \multirow{2}{*}{ s0 MIN } & $\mathrm{R}$ & $2.7 \pm 05$ & \multirow{2}{*}{0.061} \\
\cline { 2 - 3 } & $\mathrm{RD}$ & $2.4 \pm 0.5$ & \\
\hline \multirow{2}{*}{$5 \mathrm{MIN}$} & $\mathrm{R}$ & $2.5 \pm 0.5$ & \multirow{2}{*}{0.267} \\
\cline { 2 - 3 } & $\mathrm{RD}$ & $2.4 \pm 0.5$ & \\
\hline
\end{tabular}




\begin{tabular}{|c|c|c|c|}
\hline \multirow{2}{*}{$15 \mathrm{MIN}$} & $\mathrm{R}$ & $1.2 \pm 0.4$ & \multirow{2}{*}{0.008} \\
\hline & $\mathrm{RD}$ & $0.8 \pm 0.5$ & \\
\hline \multirow{2}{*}{$30 \mathrm{MIN}$} & $\mathrm{R}$ & $0.2 \pm 0.4$ & \multirow{2}{*}{0.445} \\
\hline & $\mathrm{RD}$ & $0.1 \pm 0.3$ & \\
\hline \multirow{2}{*}{60 MIN } & $\mathrm{R}$ & 0.0 & \multirow{2}{*}{1.000} \\
\hline & $\mathrm{RD}$ & 0.0 & \\
\hline \multirow{2}{*}{2 HRS } & $\mathrm{R}$ & 0.0 & \multirow{2}{*}{1.000} \\
\hline & $\mathrm{RD}$ & 0.0 & \\
\hline \multirow{2}{*}{$6 \mathrm{HRS}$} & $\mathrm{R}$ & $1.3 \pm 0.4$ & \multirow{2}{*}{0.000} \\
\hline & RD & 0.0 & \\
\hline \multirow{2}{*}{8 HRS } & $\mathrm{R}$ & $1.6 \pm 04$ & \multirow{2}{*}{0.000} \\
\hline & RD & 0.0 & \\
\hline \multirow{2}{*}{12 HRS } & $\mathrm{R}$ & $1.4 \pm 0.5$ & \multirow{2}{*}{0.000} \\
\hline & $\mathrm{RD}$ & 0.0 & \\
\hline \multirow{2}{*}{$24 \mathrm{HRS}$} & $\mathrm{R}$ & $1.4 \pm 0.5$ & \multirow{2}{*}{0.580} \\
\hline & $\mathrm{RD}$ & $1.5 \pm 0.5$ & \\
\hline
\end{tabular}

\begin{tabular}{|c|c|c|c|c|}
\hline GROUP & No. Of Rescue Analgesics & MEAN \pm S.D. & P value & SIGNIFICANCE \\
\hline R & 3.12 & $3.3 \pm 0.5$ & \multirow{2}{*}{0.0001} & HS \\
\cline { 1 - 3 } RD & 1.16 & $1.1 \pm 0.3$ & \\
\cline { 1 - 3 } & \multicolumn{2}{|c|}{ Table 7: NUMBER OF RESCUE ANALGESIA } \\
\hline
\end{tabular}

DISCUSSION: Brachial plexus block is an easy and relatively safe procedure for upper limb surgeries. Ropivacaine provided better operating conditions, but the duration of analgesia is rarely maintained for more than 4-6 h. Addition of steroid to local anesthetics effectively and significantly prolongs the duration of analgesia as well as producing earlier onset of action. Steroids are very potent antiinflammatory and immunosuppressive agents.

Addition of Dexamethasone as an adjuvant to Ropivacaine (0.5\%) for single injection supraclavicular brachial plexus block when compared to plain ropivacaine has longer duration of sensory block as is evident by our finding in Group RD, i.e., $19.5 \pm 1.5$ hrs. vs. 8.44 \pm 0.82 hrs. in Group R which is very significant, and goes in accordance with work done by Cummings Kenneth.C. ${ }^{9}$ on effect of dexamethasone on duration of brachial plexus block with ropivacaine or bupivacaine. Cummings KC III and coworkers reported longer analgesia when using ropivacaine or bupivacaine for interscalene blocks, with the effect being more potent with ropivacaine.

The observation of prolongation of sensory block was further supported by the evidence of less number of rescue analgesics in the post-operative period in Group RD when compared to group R Rescue analgesics were supplemented after 7 hrs. in Group R and after 20 hrs. in Group RD. This study demonstrates that dexamethasone significantly prolonged the analgesic effect of plain ropivacaine when used as a single injection supra clavicular block. This finding is generally consistent with previous studies. 
The magnitude of block prolongation is consistent with that observed by Parrington and colleagues ${ }^{10}$ when dexamethasone was combined with mepivacaine for supra clavicular brachial plexus block. Dexamethasone provided a faster onset of action and longer duration of analgesia without any adverse effects. In the above study $8 \mathrm{mg}$ of dexamethasone was added to $30 \mathrm{ml}$ mepivacaine $1.5 \%$ during supraclavicular brachial plexus blockade. The dexamethasone group showed a longer duration of analgesia: 332 (225-448) vs. 228 (207-263) min in the control group; whereas, the onset times of sensory and motor blockade were similar in both groups.

In another similar study done in Jan 2013 by Feroz Ahmad Dar, Mohd Rafiq Najar, Neelofar ${ }^{11}$ the effect of addition of dexamethasone to ropivacaine in supraclavicular brachial plexus block has showed similar prolongation of the duration of sensory block in the postoperative period. In reported study, significantly early onset of sensory and motor block was noticed in group DR compared to group $\mathrm{R}(\mathrm{P}<0.05)$. The early onset of action might be due to synergistic action of dexamethasone with local anesthetics on blockage of nerve fibers. The duration of pain relief (postoperative analgesia) was markedly prolonged in group RD $(14.5 \pm 0.3 \mathrm{~h})$, while it was only $8.3 \pm 0.4 \mathrm{~h}$ in group $\mathrm{R}$ $(\mathrm{P}<0.001)$.

The study done by Shrestha BR, Maharjan SK, Tabedar S.12 On Supraclavicular brachial plexus block with and without dexamethasone and reported in Kathmandu has concluded that when dexamethasone is added to local anesthetics there is significant prolongation of the duration of analgesia.

Fields K G, and Ya Deau J13 demonstrated that adding dexamethasone to local anesthetics increases the analgesic duration of single shot interscalene block

In various other studies done by Golwala MP, Swadia VN, Dhimar AA, Sridhar NV ${ }^{14}$. The pain relief by dexamethasone when added as an adjuvant to local anesthetics in supraclavicular brachial plexus block showed similar results.

In two separate studies done by Movafegh A, Razazian M, Hajimaohamadi F, Meysamie A. ${ }^{15}$ and Vieira PA, Pulai I, Tsao GC, Manikantan P, Keller B, Connelly NR ${ }^{16}$ addition of dexamethasone to lidocaine prolongs axillary brachial plexus blockade.to significant duration.

No significant changes in duration of motor block (Group RD - 7.56 \pm 0.76 ; Group R $7.28 \pm 0.89$ hrs.) No significant difference in the onset of sensory block, (Group RD was $14.96 \pm 3.0 \mathrm{~min}$ vs. 14.12 $\pm 2.1 \mathrm{~min}$ in Group R).and Onset of motor blockade (17.4 $\pm 2.9 \mathrm{~min}$ in Group RD vs. 18.12 \pm 3.4 min in Group R) was observed.

The hemodynamics intra operatively and post operatively were found to be similar in both the groups. Whatever small changes found were due to inter patient variability rather than due to a difference in the quality of the block.

CONCLUSION: From our study we conclude that addition of Dexamethasone as an adjuvant to Ropivacaine $(0.5 \%)$ for single injection supraclavicular brachial plexus block prolongs the duration of sensory block, needs less number of rescue analgesics in the post-operative period. Significant difference in the VRS pain scores was found between 6 to $10 \mathrm{hrs}$. after onset of blockade. This finding is consistent with previous studies. No significant change in onset of sensory block, onset of motor block, and duration of motor blockade was observed .Despite the concern surrounding "off-label" use of perineural adjuvants, the safety profile of dexamethasone is promising. No trial has reported neurotoxicity attributable to dexamethasone. 


\section{REFERENCES:}

1. Scott DB, Lee A, Fagan D, Bowler GM, Bloomfield P, Lundh R. Acute toxicity of ropivacaine compared with that of bupivacaine. Anesth Analg 1989; 69:563-9. [PUBMED).

2. Choi.S, Rodseth.R, Mccartney.C.J.L. Effects of dexamethasone as a local anaesthetic adjuvant for brachial plexus block: a systematic review and meta-analysis of randomized trails. Br J Anaesth, first published on line January 10, 2014 doi 10.1093/bja/aet 417.

3. Wakhlo R, Gupta V, Raina A, Gupta SD, Lahori VU. Supraclavicular plexus block: Effect of adding tramadol or butorphanol as an adjuncts to local anaesthetic on motor and sensory block and duration of post-operative analgesia. J Anaesth Clin Pharmacol 2009; 25:17-20.

4. Stan T, Goodman EJ, Bravo-Fernandez C, Holbrook CR. Adding methylprednisolone to local anesthetic increases the duration of axillary block. Reg Anesth Pain Med 2004; 29:380-1. [PUBMED].

5. Morgan GE Jr, Mikhail MS, Murray MJ. Clinical Anesthesiology, $4^{\text {th }}$ Ed. Elsevier 2006, .329-37.

6. Collins Vince J. Editor. Principles of Anesthesiology. 3 rd Ed. Philadelphia: Lea \& Febiger. 1993.

7. Desmet.M, Braems.H, Reynvoet.M, IV and perineural dexamethasone are equivalent in increasing the analgesic duration of single shot interscalene block with ropivocaine for shoulder surgery-a prospective randomized placebo controlled study. Br J Anaesth (2013), 111(3), 445-452, first published on line April 152013 doi-10.1093/bja/aet 109.

8. Cork R, Isaac I, Elsharydah A, Saleemi S, Zavisca F, Alexande L . A Comparison Of The Verbal Rating Scale And The Visual Analog Scale For Pain Assessment: Internet Journal of Anesthesiology, 2003, Vol. 8.

9. Cummings KC $3^{\text {rd }}$, Napierkowski DE, Parra-Sanchez I, Kurz A, Dalton JE, Brems JJ, et al. Effect of dexamethasone on the duration of interscalene nerve blocks with ropivacaine or bupivacaine. Br J Anaesthesia 2011; 107:446-53. [PUBMED].

10. Parrington SJ, O'Donnell D, Chan VWS, et al. Dexamethasone Added To Mepivacaine Prolongs the Duration of Analgesia After Supraclavicular Brachial Plexus Blockade. Regional Anesthesia and Pain Medicine 2010; 35:422-6.

11. Feroz Ahmad Dar, Mohd Rafiq Najar, Neelofar Jan. Effect of addition of dexamethasone to ropivacaine in supraclavicular brachial plexus block), s.l.: Indian Journal Of Pain, 2013, Vol. 27.

12. Shrestha BR, Maharjan SK, Tabedar S. Supraclavicular brachial plexus block with and without dexamethasone - A comparative study. Kathmandu Univ Med J (KUMJ) 2003; 3:158-60.

13. Fields K G, and YaDeau J dexamethasone for increasing analgesic duration of single shot interscalene block Br. J. Anaesthesia(2014)112(1):176-177 doi:10.1093/bja/eat 455.

14. Golwala MP, Swadia VN, Dhimar AA, Sridhar NV. Pain relief by dexamethasone as an adjuvant to local anaesthetics in supraclavicular brachial plexus block. J Anaesth Clin Pharmacol 2009;25:285-8

15. Movafegh A, Razazian M, Hajimaohamadi F, Meysamie A. Dexamethasone added to lidocaine prolongs axillary brachial plexus blockade. Anesth Analg 2006;102:263-7 [PUBMED]

16. Vieira PA, Pulai I, Tsao GC, Manikantan P, Keller B, Connelly NR. Dexamethasone with bupivacaine increases duration of analgesia in ultrasound-guided interscalene brachial plexus blockade. Eur J Anaesthesiol 2010; 27: 285-8. 


\section{REVIEW ARTICLE}

\section{AUTHORS:}

1. Deepraj Singh Bais

2. Geetha C.

3. Amisha Kawale

\section{PARTICULARS OF CONTRIBUTORS:}

1. Professor, Department of Anaesthesiology, Osmania Medical College, Hyderabad, A. P.

2. Assistant Professor, Department of Anaesthesiology, Osmania Medical College, Hyderabad, A. P.

3. Senior Resident, Department of Anaesthesiology, Osmania Medical College, Hyderabad, A. P.

\section{NAME ADDRESS EMAIL ID OF THE} CORRESPONDING AUTHOR:

Dr. Deepraj Singh B, 1-7-145/15, Opposite Usha Mayuri Talkies, Musheerabad, Hyderabad - 500020, Andhra Pradesh.

E-mail: drdeepraj@gmail.com

Date of Submission: 25/01/2014. Date of Peer Review: 27/01/2014. Date of Acceptance: 14/02/2014. Date of Publishing: 04/03/2014. 